\title{
Spinal Nerve Root
}

National Cancer Institute

\section{Source}

National Cancer Institute. Spinal Nerve Root. NCI Thesaurus. Code C12791.

Either of the two initial segments of a spinal nerve, the dorsal sensory nerve root or the ventral motor nerve root; once emerged, the two fuse to form a single spinal nerve. 